\title{
A multiplex PCR for differential detection of Echinococcus granulosus sensu stricto, Echinococcus multilocularis and Echinococcus canadensis in China
}

Jing-Ye Shang ${ }^{1}$, Guang-Jia Zhang ${ }^{1}$, Sha Liao', Yan Huang ${ }^{1 *}$ (10, Wen-Jie Yu', Wei He', Guang-You Yang ${ }^{2}$, Tiao-Ying Li ${ }^{1}$, Xing-Wang Chen ${ }^{1}$, Bo Zhong ${ }^{1 *}$, Qian Wang ${ }^{1}$, Qi Wang ${ }^{1}$, Rui-Rui Li ${ }^{1}$ and Hao Wang ${ }^{1}$

\begin{abstract}
Background: Echinococcosis caused by Echinococcus is one of the most major infectious diseases in north-west highland of China. E. granulosus sensu strict, E. multilocularis, and E. canadensis are known to be the only three species related to human health transmitting in the areas. To achieve targeted treatment and control of echinococcosis, the accurate identification and discrimination of the species are important. However, currently the available diagnostic approaches do not present ideal results either in accuracy or efficiency.

Methods: In the study, a set of primers were designed to aim at the three human-pathogenic Echinococcus species in China. The one-step multiplex PCR assay was developed and evaluated for the specificity and sensitivity. A total of 73 parasitic lesions and 41 fecal materials obtained from human and various animals collected in the clinic and the field were tested to assess the applicability of this method.

Results: The multiplex PCR effectively detected the individual DNA from the targeted species and their random mixtures generating with distinguishable expected size of products. The detection limit of the assay for each of the three species was $5 \mathrm{pg} / \mu \mathrm{l}$ when they were tested separately. When DNA mixtures of the targeted species containing the same concentration were used as templates, the lowest amount of DNA which can be detected was $50 \mathrm{pg} / \mu \mathrm{l}, 10 \mathrm{pg} / \mathrm{\mu l}$ and 5 $\mathrm{pg} / \mu \mathrm{l}$ for E. granulosus S. S., E. multilocularis, and E. canadensis respectively. No cross-reactivity was observed when DNA from eight genetically close species was used as control templates. The multiplex PCR identifications of all samples were in line with the original sequencing results except for those infected with E. shiquicus, which showed negative signals in the developed assay. Of all the tested stool materials, 16 were previously found positive for Echinococcus by visual and microscopic examination. Among these 16 samples, 13 were confirmed by the multiplex PCR, and the other three tested negative. Additionally, the multiplex PCR identified another 14 positive feces from the remained 25 stool samples which absence of worms.
\end{abstract}

Conclusions: The developed multiplex PCR shows advantages in fast diagnosis and large-scale epidemiological investigation, which proven to be a promising tool utilized in clinic and surveillance system.

Keywords: Echinococcosis, Echinococcus granulosus s. S., Echinococcus multilocularis, Echinococcus canadensis, Multiplex PCR

\footnotetext{
*Correspondence: huangyancdc@163.com; zhongbo1968@163.com

'Institute of Parasitic Diseases, Sichuan Center for Disease Control and

Prevention, Chengdu, Sichuan, People's Republic of China

Full list of author information is available at the end of the article
}

(c) The Author(s). 2019 Open Access This article is distributed under the terms of the Creative Commons Attribution 4.0 International License (http://creativecommons.org/licenses/by/4.0/), which permits unrestricted use, distribution, and reproduction in any medium, provided you give appropriate credit to the original author(s) and the source, provide a link to the Creative Commons license, and indicate if changes were made. The Creative Commons Public Domain Dedication waiver (http://creativecommons.org/publicdomain/zero/1.0/) applies to the data made available in this article, unless otherwise stated. 


\section{Multilingual abstracts}

Please see Additional file 1 for translations of the abstract into the five official working languages of the United Nations.

\section{Background}

Echinococcosis, caused by the infection of one or more of nine species within the genus Echinococcus, is among the most neglected zoonoses distributed globally, bringing about great public health concerns and economic losses [1-3]. In China, where 368 endemic counties distributed in nine provinces with an estimated 166098 cases nationally [4], four species coexisted $[5,6]$. E. granulosus sensu strict (G1-3) and E. canadensis (G6-8, 10) infections lead to cystic echinococcosis (CE), which is the most major type of the disease [7]. E. multilocularis infection result in alveolar echinococcosis (AE), also called as "parasite cancer", is one of the most lethal parasitic infections in humans [8]. E. shiquicus, the sister species of E. multilocularis [9], has shown no correlations with human or domestic animal infections so far [10-12]. Because the treatment principles and chemotherapeutic effects vary much between $\mathrm{CE}$ and $\mathrm{AE}[13$, $14]$, and the life cycles, transmission patterns and related risk factors of these species are quite different [15], the accurate detection and identification of the species are extraordinarily vital in effective treatment and targeted control of ecinococcosis.

Imaging examination, immunological detection, histopathological analysis, visual and microscopic observation are the main methods extensively used in clinic and surveillance networks. Unfortunately, the correctness and accuracy of the results determined by the approaches have been shown to be insufficient sometimes [16-19]. Furthermore, none of the diagnostic methods can precisely discriminate the species within E. granulosus sensu lato. Incorrect or inaccurate diagnosis can lead to serious and even fatal consequences for patients. Without detailed species-level information, it is hard to evaluate the risk level of the pathogen species transmitted in the environment, so as to adjust the prevention and control strategy in time. PCR-based molecular detections therefore have been adopted to conduct the differential diagnosis of echinococcosis.

Currently, most of the known PCR-related assays, designed to detect single species with singular amplification, or use a generic PCR followed with DNA sequencing/ enzyme reaction for species discrimination, or achieve higher sensitivity with a nested-PCR consisted of two steps, cannot meet the needs of rapid diagnosis or largescale investigation, especially for areas where multiple Echinococcus species are co-distributed. Multiplex PCR, a one-tube amplification assay for simultaneous detection of all targeted species, is fast, labor-saving and cost- effective.
It is highly applicable to differentiate the pathogens of echinococcosis in the co-transmitted regions. Some multiplex PCR assays have been developed for the detection of species within Echinococcus [20-22]. But none of them were aimed at the simultaneously identification of E. granulosus s. s., E. multilocularis, and E. canadensis.

In this study, we describe the development and evaluation of a multiplex PCR assay for the differential detection of three human-pathogenic Echinococcus species having been confirmed present in China.

\section{Methods}

\section{Sample collection}

For the initial primers screening and the validation of sensitivity and specificity, a panel of isolates from parasite lesions and adult worms were used, including $E$. granulosus s. s., E. multilocularis, E. canadensis (G6/7), E. canadensis (G8/10) which are the detection targets, E. shiquicus, Taenia taeniaeformis, Hymenolepis diminuta, T. pisiformis, T. saginata, T. solium, T. asiatica, and $T$. serialis used as negative controls (Table 1).

For the verification of the applicability for the detection of human and animal infections, 36, 14, and 23 parasite lesions derived respectively from echinococcosis patients, infected yaks and small mammals were used, along with 41 stool materials obtained after arecoline purgation of domestic dogs (Table 2).

All the tissue samples were stored in 95\% ethanol before use. Stool samples were pre-examined by naked-eye and optical microscope.

\section{DNA extraction and pre-sequencing}

Genomic DNA from tissue and fecal samples were extracted respectively using the DNeasy Blood \& Tissue Kit (Qiagen, Germany) and the QIAamp DNA Stool Mini Kit (Qiagen, Germany) according to the manufacturer's

Table 1 Cestodes used to establish the multiplex PCR and to evaluate the sensitivity and specificity of this assay

\begin{tabular}{lll}
\hline Parasite species & Parasite stage & Host origin \\
\hline Echinococcus granulosus S. s. & Metacestode lesion & Human \\
E. multilocularis & Metacestode lesion & Human \\
E. canadensis (G6/7) & Metacestode lesion & Human \\
E. canadensis (G8/10) & Metacestode lesion & Sheep \\
E. shiquicus & Metacestode lesion & Plateau pika \\
Taenia taeniaeformis & Metacestode lesion & Mouse \\
Hymenolepis diminuta & Adult worm & Mouse \\
T. pisiformis & Metacestode lesion & Rabbit \\
T. saginata & Adult worm & Human \\
T. solium & Adult worm & Human \\
T. asiatica & Adult worm & Human \\
T. serialis & Adult worm & Dog \\
\hline
\end{tabular}


Table 2 Samples used for the assessment of the applicability of the multiplex PCR for the detection of human and animal infections

\begin{tabular}{lll}
\hline Host origin & Parasite stage & No. of samples \\
\hline Human & Metacestode lesion & 36 \\
Yak & Metacestode lesion & 14 \\
Small mammal & Metacestode lesion & 23 \\
Dog & Purged feces & 41 \\
Total & & 77 \\
\hline
\end{tabular}

protocols. DNA concentration were determined using a Nano Drop spectrophotometer (Thermo Scientific, USA).

All the parasite samples employed in the study were pre-determined to species-level based on an 880-bp sequence of partial cytochrome c oxidase subunit I ( $\operatorname{cox} 1)$ gene [23].

\section{Primer design and selection}

The complete mitochondrial genome sequence of $E$. granulosus s. s. (GenBank accession No. NC_008075.1, KJ559023.1), E. multilocularis (No. NC_000928.2, AB018440.2), and E. canadensis (G6/7, No. NC_011121.1, AB235847.1, and G8/10, No. AB235848.1, AB745463.1) were retrieved from the National Center for Biotechnology Information database (NCBI). The sequences were aligned using MEGA7 (www.megasoftware.net) [24]. Specific-conserved regions were found and used to design the primer pairs by Oligo 7 (DBA Oligo, Inc., USA) [25]. After checking with NCBI primer-BLAST, the primer candidates which showed no cross-hybridization to non-target fragments were preliminarily tested for specificity by singlex amplification. Primers that yielded only specific products with appropriate length size were combined for multiplex reactions. The sets of primers were evaluated on specificity, sensitivity and capability of simultaneous detection of target species. The ones with desired specificity and sensitivity producing distinguishable size of PCR products were selected and further assessed on applicability using appropriate numbers of clinical and field samples.

\section{Multiplex PCR}

Multiplex PCR was performed in a $25 \mu \mathrm{l}$ reaction mixture containing $1 \times$ GoTaq Hot Start Green Master Mix (Promega, USA), $6.5 \mu \mathrm{l}$ of $\mathrm{dd}_{2} \mathrm{O}$ and $1 \mu \mathrm{l}$ of DNA template. The final concentrations of the primers used to detect each species are listed in Table 3.

PCR was carried out by an initial denaturation at $94{ }^{\circ} \mathrm{C}$ for $2 \mathrm{~min}$, followed by 40 cycles of denaturation at $94{ }^{\circ} \mathrm{C}$ for $30 \mathrm{~s}$, annealing at $55^{\circ} \mathrm{C}$ for $45 \mathrm{~s}$, extension at $72^{\circ} \mathrm{C}$ for $60 \mathrm{~s}$, and a final extension at $72^{\circ} \mathrm{C}$ for $5 \mathrm{~min}$ in a PCR thermocycler (ABI2720, Applied Biosystems, USA).

Amplified products were checked for size using 2\% agarose gel electrophoresis and visualized on a UV transilluminator (Universal Hood II, Bio-Rad, Germany). Positive-PCR products were sent for sequencing to confirm the identity on both strands at Tsingke Biological Technology, China.

\section{Detection capability of single and mixed infection}

Genomic DNA from E. granulosus s. s., E. multilocularis, E. canadensis, and their random mixtures were used in the multiplex PCR to assess the feasibility of this method in detecting and discriminating the targeted species individually and simultaneously.

\section{Evaluation of specificity}

To test the specificity of the reaction, multiplex PCR was performed using DNA templates prepared from the three targeted species, along with another eight different non-targeted parasite isolates belonging to the tapeworm lineage as the same as Echinococcus.

\section{Assessment of sensitivity}

Serial dilutions of genomic DNA from E. granulosus s. S., E. multilocularis, E. canadensis (G6/7) respectively, and their mixtures containing equal concentrations of the three targeted species were applied in the multiplex PCR at final concentrations of $1,0.5,0.1,0.05,0.01$, $0.005,0.001 \mathrm{ng} / \mu \mathrm{l}$ to determine the sensitivity of the assay.

Table 3 Primers designed for detection of Echinococcus granulosus S. S., E. multilocularis and E. canadensis in the study

\begin{tabular}{lllcr}
\hline Targeted species & Primer name & Sequences $\left(5^{\prime} \rightarrow 3^{\prime}\right)$ & Expected product length & Final concentration $(\mathrm{nmol} / \mathrm{L})$ \\
\hline E. granulosus s. $\mathrm{s}$. & $\mathrm{g} / \mathrm{f}$ & GTCTGTGTTTCTACCATTG & 811 & 200 \\
& $\mathrm{~g} / \mathrm{r}$ & GACCCGTACAAACATATATCAAC & & \\
E. multilocularis & $\mathrm{m} / \mathrm{f}$ & TTGTTTTTGTGTACTGTAGG & 457 & 600 \\
& $\mathrm{~m} / \mathrm{r}$ & CTATACAGACATTGATTACCATAA & 315 & 200 \\
E. canadensis & $\mathrm{c} / \mathrm{f}$ & GTAAGTCTAAGTTGGTATTATTCAC & & \\
& $\mathrm{c} / \mathrm{r}$ & CTTATTAAACAACACAAAAATACTAAATG & \\
\hline
\end{tabular}




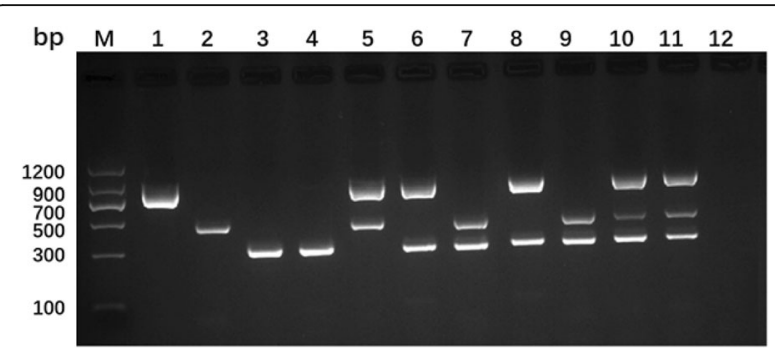

Fig. 1 Multiplex PCR products from E. granulosus S. S., E. multilocularis, E. canadensis (G6/7 and G8/10) and their combinations. Lane M, Molecular weight markers (DNA marker II, Tiangen Biotech); lane 1, E. granulosus S. S.; lane 2, E. multilocularis; lane 3, E. canadensis (G6/7); lane 4, E. canadensis (G8/10); lane 5, E. granulosus S. S. and E. multilocularis; lane 6, E. granulosus s. S. and E. canadensis (G6/7); lane 7, E. multilocularis and E. canadensis (G6/7); lane 8, E. granulosus s. s. and E. canadensis (G8/10); lane 9, E. multilocularis and E. canadensis (G8/10); lane 10, E. granulosus S. S., E. multilocularis and E. canadensis (G6/7); lane 11, E. granulosus S. S., E. multilocularis and E. canadensis (G8/10); lane 12, no template control

\section{Applicability for the detection of human and animal infection}

A number of clinical lesion samples, as well as suspected lesions separated from animals, and feces harvested from purged owned dogs were used for further assessment of the assay. DNA extracted from all the isolates were randomly re-coded and then tested blindly.

\section{Results}

\section{Primer design and selection}

Having tested several primers and their combinations, three pairs of primers target on ATPase subunit 6 (atp6) gene and its flanking region of E. granulosus s. S., NADH dehydrogenase subunit 1 ( $n d 1$ ) gene of E. multilocularis, and large ribosomal RNA ( $r r n L)$ gene of E. canadensis were chosen for multiplex PCR amplification. The information of the primers used in the method was presented in Table 3.

\section{Detection of single and mixed infection}

The designed primer combination is able to discriminate among E. granulosus s. S., E. multilocularis, and E. canadensis, and to detect the random mixtures of their DNA simultaneously in one-tube reaction (Fig. 1). Each pair of primers generated specified products with expected size which presented clear and distinct bands on agarose gel. Using primer $\mathrm{c} / \mathrm{f}$ and $\mathrm{c} / \mathrm{r}$, the multiplex PCR assay identified the genotype 6/7 and genotype 8/10 of E. canadensis resulting in bands with the same size.

\section{Specificity and sensitivity of the multiplex PCR}

No cross-reaction was observed when DNA templates adopted from eight relevant but non-targeted parasites within the family Taeniidae were used (Fig. 2). The amplicons of E. granulosus s. s., E. multilocularis, and $E$. canadensis were detectable with amount as low as $5 \mathrm{pg} /$ $\mu \mathrm{l}$ when DNA from each of the targeted species was tested individually (Fig. 3). When the assay was performed using the templates consisted of DNA mixtures of these three species at the same concentration, the detection limit was $50 \mathrm{pg} / \mu \mathrm{l}, 10 \mathrm{pg} / \mu \mathrm{l}$ and $5 \mathrm{pg} / \mu \mathrm{l}$ for $E$. granulosus s. s., E. multilocularis, and E. canadensis respectively (Fig. 3).

\section{Detection of human and animal infection samples}

The developed multiplex PCR method was used to test samples obtained from patients and different infected animals. The detection results were shown in Table 4.

DNA isolated from parasite lesions taken from humans and domestic animals was all successfully amplified, and the multiplex PCR identification results agreed with the initial sequencing results.

Additionally, seven out of 23 samples derived from small mammals were detected as E. multilocularis, which are consistent with previous sequencing results. The other 16 samples pre-identified as E. shiquicus by sequencing presented negative result in the multiplex PCR.

The multiplex PCR results for the fecal samples were in agreement with the pre-sequencing records, except

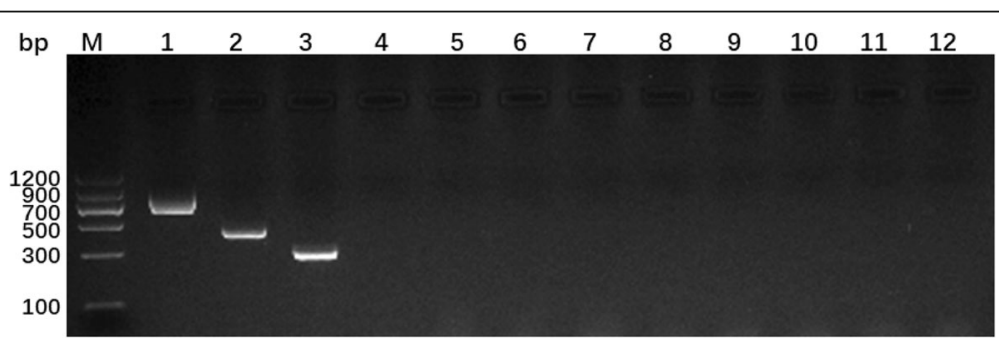

Fig. 2 Multiplex PCR products from three targeted and eight genetically related but non-targeted parasites. Lane M, Molecular weight markers (DNA marker II, Tiangen Biotech); lane 1, E. granulosus s. S.; lane 2, E. multilocularis; lane 3, E. canadensis (G6/7); lane 4, E. shiquicus; lane 5, T. saginata; lane 6, T. solium; lane 7, T. asiatica; lane 8, T. serialis; lane 9, T. taeniaeformis; lane 10, T. pisformis; lane 11, H. diminuta; lane 12, no template control 


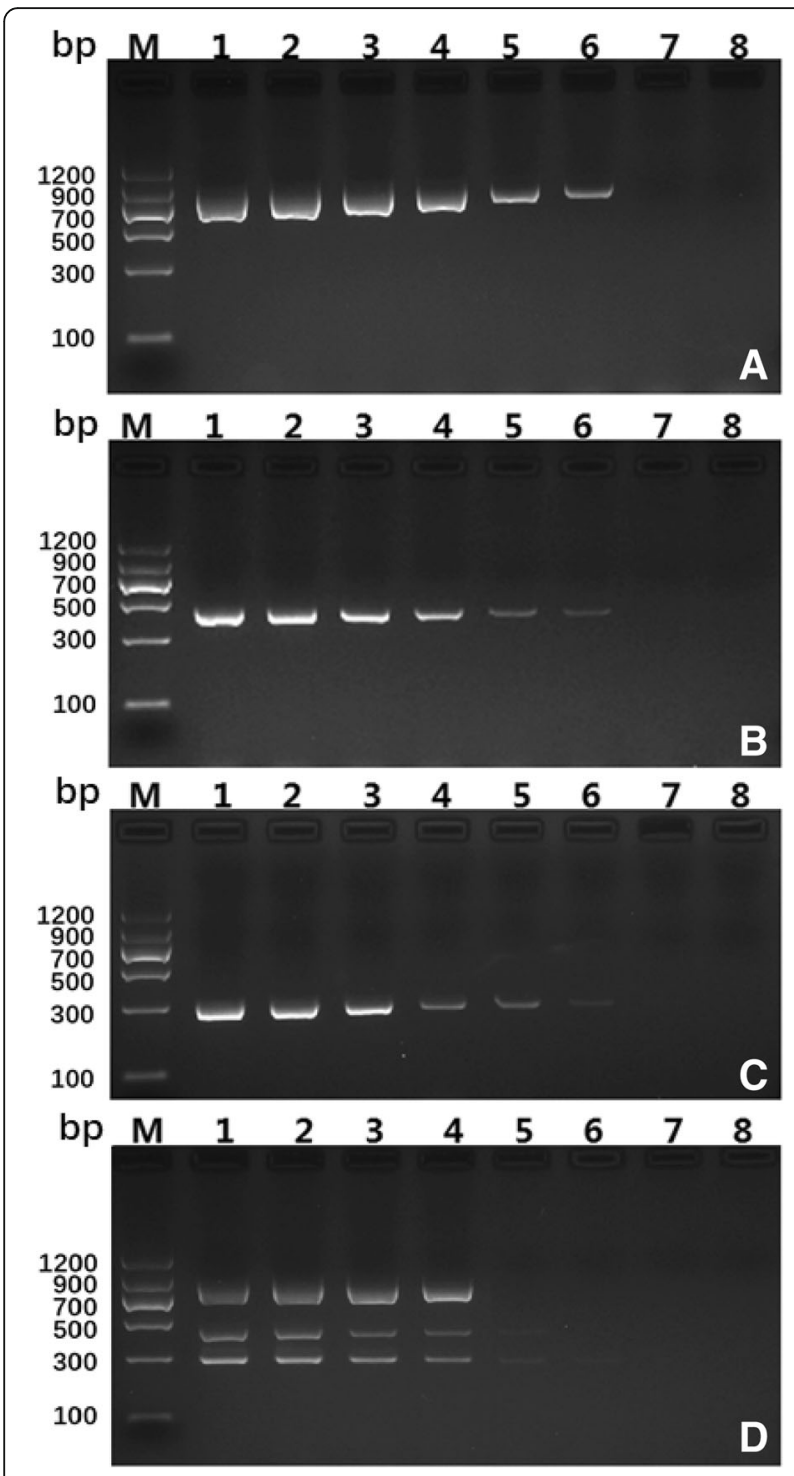

Fig. 3 Multiplex PCR products from (a) E. granulosus S. S., (b) E. multilocularis, (c) E. canadensis (G6/7) and (d) their mixtures. Lane M, Molecular weight markers (DNA marker II, Tiangen Biotech); lane 1, DNA templates with final concentration of $1 \mathrm{ng} / \mu \mathrm{l}$; lane 2, DNA templates with final concentration of $0.5 \mathrm{ng} / \mu \mathrm{l}$; lane 3, DNA templates with final concentration of $0.1 \mathrm{ng} / \mu \mathrm{l}$; lane 4, DNA templates with final concentration of $0.05 \mathrm{ng} / \mu \mathrm{l}$; lane 5, DNA templates with final concentration of $0.01 \mathrm{ng} / \mathrm{\mu l}$; lane 6, DNA templates with final concentration of $0.005 \mathrm{ng} / \mu \mathrm{l}$; lane 7, DNA templates with final concentration of $0.001 \mathrm{ng} / \mu \mathrm{l}$; lane 8 , No template control

one, which showed negative signals in the assay was previously determined as E. shiquicus.

Furthermore, of all the tested stool samples, 16 were found to contain adult worms of Echinococcus by visual and microscopic examination. Among the 16 positive samples, 13 were detected as E. multilocularis by the multiplex PCR, and the remained three presented negative both in the current assay and previous molecular identification. Moreover, 14 microscopic-negative samples generated positive signals in the multiplex PCR (Table 5) .

\section{Discussion}

Echinococcosis is one of the biggest public health challenges in China. The species composition of the causative agents leading to the disease transmitted in this area is rather complex [6, 26-28]. At least four Echinococcus species are proven to be co-endemic, 3 of which are related to human echinococcosis. To achieve rapid diagnosis and targeted prevention of echinococcosis, it is necessary to develop an accurate and efficient method to identify the species for clinical and epidemiological use.

In the study, a fast and convenient multiplex PCR assay was established to identify and discriminate $E$. granulosus s. S., E. multilocularis, and E. canadensis in a single tube reaction. Closely related parasite species which commonly detected in the same animal hosts inhabit in the endemic areas of Sichuan were picked to test the cross-reactivity of the assay. No false positive signals were detected among them. However, further validation were suggested if the assay is applied to other endemic regions with the existence of any other related parasites that may result in non-specific amplifications in the multiplex PCR system.

Domestic animals are known to be the main intermediate hosts of E. granulosus s. S., whilst E. multilocularis and E. shiquicus are harbored by small mammal hosts. The results of the validation suggested that the developed method possesses an ideal capability of detecting the first two targeted species, and does not show any cross-reactivity with the third species testified by multiplex PCR-negative in the study. E. shiquicus is a newly discovered species that appears to be exclusive in China [12]. For now, no evidence was found to indicate it has any pathogenic potential to humans. Therefore, this species is not taken as the detection target in the study since it is not the primary concerns in the control program. However, of course, the method could be further improved to a quadruplex PCR utilized in ecological or biological investigation of Echinococcus species by adding a pair of $E$. shiquicus-specific primers.

The advantage of the multiplex PCR method becomes more obvious when it is used for the test of the causative pathogens in definitive hosts other than intermediate hosts, because miss detection of mixed species infections are more likely to happen in stools compared to tissues, even though this kind of samples count just for a small portion of the total. None of the fecal materials showed co-infection in the study owing to the lack of such samples, but the results of the spiked DNA samples have fully proved that the developed assay is capable of 
Table 4 Detection results of the samples used to validate the applicability of the multiplex PCR

\begin{tabular}{|c|c|c|c|c|c|}
\hline \multirow[t]{2}{*}{ Host } & \multirow[t]{2}{*}{ Species } & \multicolumn{4}{|l|}{ Multiple PCR identification } \\
\hline & & Echinococcus granulosus s. s. & E. multilocularis & E. canadensis & Negative \\
\hline \multirow[t]{3}{*}{ Human $(n=36)$} & E. granulosus s. S. & 22 & 0 & 0 & 0 \\
\hline & E. multilocularis & 0 & 13 & 0 & 0 \\
\hline & E. canadensis(G6/7) & 0 & 0 & 1 & 0 \\
\hline Yak $(n=14)$ & E. granulosus s. s. & 14 & 0 & 0 & 0 \\
\hline \multirow[t]{2}{*}{ Small mammal $(n=23)$} & E. multilocularis & 0 & 7 & 0 & 0 \\
\hline & E. shiquicus & 0 & 0 & 0 & 16 \\
\hline \multirow[t]{4}{*}{$\operatorname{Dog}(n=41)$} & E. granulosus s. s. & 1 & 0 & 0 & 0 \\
\hline & E. multilocularis & 0 & 26 & 0 & 0 \\
\hline & E. shiquicus & 0 & 0 & 0 & 1 \\
\hline & Negative & 0 & 0 & 0 & 13 \\
\hline
\end{tabular}

detecting double and triple mixed infections of the targeted species effectively.

However, the sensitivity of this assay is considered to be not good enough when it is applied to detect the infection in canine faces. Basing on the data that nuclear DNA is about 8 pg per egg [29], at least 15 eggs are need to generate a positive result using the developed method, even more for mixed infections. Therefore, to avoid false negative result from low infection, the enlargement of test volume is suggested to enrich the pathogens in feces. Previously reported multiplex PCR methods showed higher sensitivities, but they were targeted on $E$. shiquicus, Taenia spp. and E. granulosus s.l. [21, 22].

The evaluation results based on various samples obtained from human and different animal hosts indicated that the multiplex PCR developed in this study is applicable for clinical and epidemiological use, particularly for the confirmation and classification of human echinococcosis. Further optimization will be implemented.

In addition, similar as reported before [22], a weak correlation was observed between the results of purgation and the multiplex PCR. Fourteen fecal materials which had no Echinococcus adults examined by naked eyes and microscope showed positive bands in the multiplex PCR. The followed sequencing results exclude the possibility that the amplicons yielded from non-specific amplification. A previous study revealed that about $40 \%$ dogs with Echinococcus infections were not sensitive to arecoline purgation resulting in false negatives (absence of worms in purged excretions) [30]. The results in the study suggested that the developed assay could detect this kind of purge-negative cases which might result from low infection intensities. On the other hand, three samples contained Echinococcus worms showed false negative outcomes in the multiplex PCR. Since none of these samples gave positive signals at the initial molecular identification either, the inconsistence might be due to the inhomogeneous distribution of the pathogens in feces.

As increasingly being identified in recent years, genotype G6/7 is now believed to have a much broader geographical distribution, wider host range and more significant impacts on human health in China and worldwide [6, 31, 32]. Three cases of genotype G8/10 infection were documented in China at present, two of which found on the Qinghai-Tibetan Plateau indicated a high probability that the transmission of this genotype occurs in the area [27, 33, 34]. Since the distribution and prevalence of genotype G6/7 and G8/10 in China are still unclear, thus the identification of them should be taken into account within the routine diagnosis and surveillance system.

The taxonomic status of E. canadensis is highly controversial, which genotype G6/7 and G8/10 tend to be regarded as two different species now [35]. However, the proposal of revision has not reach a consesus yet. Since toxomony is not the primary research issue in the study, and the number of cases caused by the infection of the two genotypes especially G8/10 are much lower compared to E.granulosus s. s. and E.multilocularis.

Table 5 Comparison of the results of the fecal materials between visual / microscopic examination and molecular detections

\begin{tabular}{|c|c|c|c|c|c|c|c|}
\hline \multirow{2}{*}{$\begin{array}{l}\text { Visual and } \\
\text { microscopic } \\
\text { examination } \\
\end{array}$} & \multicolumn{4}{|l|}{ Pre-sequencing } & \multicolumn{3}{|c|}{ Multiple PCR identification } \\
\hline & Echinococcus granulosus s. S. & E. multilocularis & E. shiquicus & Negative & E. granulosus s. s. & E. multilocularis & Negative \\
\hline Positive & 0 & 13 & 0 & 3 & 0 & 13 & 3 \\
\hline Negative & 1 & 13 & 1 & 10 & 1 & 13 & 11 \\
\hline Total & 1 & 26 & 1 & 13 & 1 & 26 & 14 \\
\hline
\end{tabular}


Therefore, the study is aimed at detecting the genotype G6/7 and G8/10 at the same time without distinguishment. DNA from the genotype G6/7 and G8/10 were both used to validate the multiplex PCR. The result showed that the two DNA samples were successfully amplified and generated PCR products with same expected size on gel. Both the genotype G6/7 and G8/10 can be identified in the developed assay just as designed. It should be noted that, however, the distribution and host selection of the two genotypes are known to be different [36], and human response to them may vary too. The discrimination between the genotype G6/7 and G8/ 10 is needed eventually. Besides, thus far samples of these genotypes obtained to verify this assay were limited, further examinations with more specimens are required.

\section{Conclusions}

The new single-tube multiplex PCR method that allows rapid, accurate and simultaneous detection of $E$. granulosus s. s., E. multilocularis and E. canadensis was developed and assessed in the study. The results suggested that the method has potential application in fast detection and large-scale screening, which makes it a promising candidate as the key technology for clinical diagnosis and environmental monitoring.

\section{Additional file}

Additional file 1: Multilingual abstracts in the five official working languages of the United Nations. (PDF $271 \mathrm{~kb}$ )

\section{Abbreviations}

AE: Alveolar echinococcosis; BLAST: Basic local alignment search tool; CE: Cystic echinococcosis; DNA: Deoxyribonucleic acid; NCBI: National center for biotechnology information; PCR: Polymerase chain reaction

\section{Acknowledgments}

Many thanks to Professor Guang-You Yang, Dr. Tiao-Ying Li, Xing-Wang Chen for kindly providing Echinococcus and Taenia DNA samples.

\section{Authors' contributions \\ SJY designed the assay, performed the lab works and draft the manuscript. $H Y$ revised the manuscript and provided coordination for the study. ZGJ, LS, YWJ, HW WQ and WQ participated in fieldwork and collected most of the samples. ZB provided financial supports for this study. YGY, LTY and CXW generously provided some of the DNA samples. LRR and WH helped collected some data. All authors commented on the manuscript draft and read and approved the final manuscript.}

\section{Funding}

This study was supported by the Scientific Research Project of Health and Family Planning Commission of Sichuan Province (No. 17PJ440).

\section{Availability of data and materials}

The data supporting the conclusions of this article are included within the article.

\section{Ethics approval and consent to participate}

The study was approved by the Ethical Committee of Sichuan Provincial Center for Diseases Control and Prevention.
Consent for publication

Not applicable.

\section{Competing interests}

The authors declare that they have no competing interests.

\section{Author details}

${ }^{1}$ Institute of Parasitic Diseases, Sichuan Center for Disease Control and Prevention, Chengdu, Sichuan, People's Republic of China. ${ }^{2}$ Department of Parasitology, College of Veterinary Medicine, Sichuan Agricultural University, Chengdu, Sichuan, People's Republic of China.

Received: 23 April 2019 Accepted: 19 July 2019

Published online: 30 July 2019

\section{References}

1. Deplazes P, Rinaldi L, Alvarez Rojas CA, Torgerson PR, Harandi MF, Romig T, et al. Global distribution of alveolar and cystic echinococcosis. Adv Parasitol. 2017;95:315-493.

2. Kern P, Menezes da Silva A, Akhan O, Mullhaupt B, Vizcaychipi KA, Budke C, et al. The echinococcoses: diagnosis, clinical management and burden of disease. Adv Parasitol. 2017;96:259-369.

3. Nakao M, Lavikainen A, Yanagida T, Ito A. Phylogenetic systematics of the genus Echinococcus (Cestoda: Taeniidae). Int J Parasitol. 2013;43(12-13):1017-29.

4. Wu WP, Wang H, Wang Q, Zhou XN, Wang LY, Zheng CJ, et al. A nationwide sampling survey on echinococcosis in China during 2012-2016. Chin J Parasitol Paras Dis. 2018;36(01):1-14 (in Chinese).

5. Nakao M, Li T, Han X, Ma X, Xiao N, Qiu J, et al. Genetic polymorphisms of Echinococcus tapeworms in China as determined by mitochondrial and nuclear DNA sequences. Int J Parasitol. 2010;40(3):379-85.

6. Ma J, Wang H, Lin G, Zhao F, Li C, Zhang T, et al. Surveillance of Echinococcus isolates from Qinghai, China. Vet Parasitol. 2015;207(1-2):44-8.

7. Wang GQ. Epidemiological survey on echinococcosis in China. Shanghai: Shanghai Scientific \& Technical Publishers; 2016. (in Chinese)

8. Bresson-Hadni S, Miguet JP, Mantion G, Giraudoux P, Vuitton DA. Alveolar echinococcosis: a disease comparable to a slow growing cancer. Bull Acad Natl Med. 2008;192(6):1131-8 discussion 1139.

9. McManus DP. Current status of the genetics and molecular taxonomy of Echinococcus species. Parasitology. 2013;140(13):1617-23.

10. Li T, Ito A, Nakaya K, Qiu J, Nakao M, Zhen R, et al. Species identification of human echinococcosis using histopathology and genotyping in northwestern China. Trans R Soc Trop Med Hyg. 2008;102(6):585-90.

11. Shang J, Zhang G, Yu W, He W, Wang Q, Zhong B, et al. Molecular characterization of human echinococcosis in Sichuan, Western China. Acta Trop. 2018;190:45-51.

12. Xiao N, Qiu J, Nakao M, Li T, Yang W, Chen X, et al. Echinococcus shiquicus, a new species from the Qinghai-Tibet plateau region of China: discovery and epidemiological implications. Parasitol Int. 2006;55 Suppl:S233-6.

13. McManus DP, Gray DJ, Zhang W, Yang Y. Diagnosis, treatment, and management of echinococcosis. BMJ. 2012;344:e3866.

14. Siles-Lucas M, Casulli A, Cirilli R, Carmena D. Progress in the pharmacological treatment of human cystic and alveolar echinococcosis: compounds and therapeutic targets. PLoS Negl Trop Dis. 2018:12(4):e0006422.

15. Romig T, Deplazes P, Jenkins D, Giraudoux P, Massolo A, Craig PS, et al. Ecology and life cycle patterns of Echinococcus species. Adv Parasitol. 2017; 95:213-314

16. Al-Sabi MN, Kapel CM, Deplazes P, Mathis A. Comparative copro-diagnosis of Echinococcus multilocularis in experimentally infected foxes. Parasitol Res. 2007;101(3):731-6

17. Dybicz M, Borkowski PK, Padzik M, Baltaza W, Chomicz L. Molecular determination of suspected alveolar echinococcosis requiring surgical treatment in human cases from Poland. Ann Parasitol. 2018;64(4):339-42

18. Maddah G, Abdollahi A, Sharifi-Nooghabi R, Tavassoli A, Rajabi-Mashadi MT, Jabbari-Nooghabi A, et al. Difficulties in the diagnosis and management of alveolar hydatid disease: a case series. Caspian J Intern Med. 2016;7(1):52-6.

19. Tawfeek GM, Elwakil HS, El-Hoseiny L, Thabet HS, Sarhan RM, Awad NS, et al. Comparative analysis of the diagnostic performance of crude sheep hydatid cyst fluid, purified antigen $B$ and its subunit (12 Kda), assessed by ELISA, in the diagnosis of human cystic echinococcosis. Parasitol Res. 2011;108(2):371-6. 
20. Boubaker G, Macchiaroli N, Prada L, Cucher MA, Rosenzvit MC, Ziadinov I, et al. A multiplex PCR for the simultaneous detection and genotyping of the Echinococcus granulosus complex. PLoS Negl Trop Dis. 2013;7(1):e2017.

21. Liu CN, Lou ZZ, Li L, Yan HB, Blair D, Lei MT, et al. Discrimination between E. granulosus sensu stricto, E. multilocularis and E. shiquicus using a multiplex PCR assay. PLoS Negl Trop Dis. 2015;9(9):e0004084.

22. Trachsel D, Deplazes $P$, Mathis A. Identification of taeniid eggs in the faeces from carnivores based on multiplex PCR using targets in mitochondrial DNA. Parasitology. 2007;134(Pt 6:911-20.

23. Nakao M, Sako Y, Yokoyama N, Fukunaga M, Ito A. Mitochondrial genetic code in cestodes. Mol Biochem Parasitol. 2000;111(2):415-24.

24. Kumar S, Stecher G, Tamura K. MEGA7: molecular evolutionary genetics analysis version 7.0 for bigger datasets [J]. Mol Boil Evol. 2016;33(7):1870-4.

25. Rychlik W. OLIGO 7 primer analysis software $[M] / / P C R$ primer design: Humana Press; 2007. p. 35-59.

26. Cao M, Chen K, Li W, Ma J, Xiao Z, Wang H, et al. Genetic characterization of human-derived hydatid fluid based on mitochondrial gene sequencing in individuals from northern and western China. J Helminthol. 2018;17:1-5.

27. Wu Y, Li L, Zhu G, Li W, Zhang N, Li S, et al. Mitochondrial genome data confirm that yaks can serve as the intermediate host of Echinococcus canadensis (G10) on the Tibetan plateau. Parasit Vectors. 2018;11(1).

28. Zhang T, Yang D, Zeng Z, Zhao W, Liu A, Piao D, et al. Genetic characterization of human-derived hydatid cysts of Echinococcus granulosus sensu lato in Heilongjiang Province and the first report of $\mathrm{G} 7$ genotype of $E$. canadensis in humans in China. PLoS One. 2014;9(10):e109059.

29. Gottstein B, Mowatt MR. Sequencing and characterization of an Echinococcus multilocularis DNA probe and its use in the polymerase chain reaction. Mol Biochem Parasitol. 1991;44(2):183-93.

30. Lahmar S, Lahmar S, Boufana B, Bradshaw H, Craig PS. Screening for Echinococcus granulosus in dogs: comparison between arecoline purgation, CoproELISA and coproPCR with necropsy in pre-patent infections. Vet Parasitol. 2007;144(3-4):287-92.

31. Alvarez Rojas CA, Romig T, Lightowlers MW. Echinococcus granulosus sensu lato genotypes infecting humans--review of current knowledge. Int J Parasitol. 2014:44(1):9-18.

32. Ito A, Nakao M, Lavikainen A, Hoberg E. Cystic echinococcosis: future perspectives of molecular epidemiology. Acta Trop. 2017;165:3-9.

33. Yang $D$, Zhang $T$, Zeng Z, Zhao W, Zhang W, Liu A. The first report of human-derived G10 genotype of Echinococcus canadensis in China and possible sources and routes of transmission. Parasitol Int. 2015;64(5):330-3.

34. Hua R, et al. Echinococcus canadensis G8 tapeworm infection in a sheep, China, 2018. Emerg Infect Dis. 2019;25(7):1420-2.

35. Laurimae T, Kinkar L, Moks E, Romig T, Omer RA, Casulli A, et al. Molecular phylogeny based on six nuclear genes suggests that Echinococcus granulosus sensu lato genotypes $\mathrm{G} 6 / \mathrm{G} 7$ and $\mathrm{G} 8 / \mathrm{G} 10$ can be regarded as two distinct species. Parasitology. 2018;145(14):1929-37.

36. Shang JY, Zhang GJ, He W, Yu WJ, Liao S, Wang Q, et al. Taxonomy and molecular epidemiology of Echinococcus granulosus complex causing cystic echinococcosis. Chin J Parasitol Parasit Dis. 2018;36(2):166-73 (in Chinese).

Ready to submit your research? Choose BMC and benefit from:

- fast, convenient online submission

- thorough peer review by experienced researchers in your field

- rapid publication on acceptance

- support for research data, including large and complex data types

- gold Open Access which fosters wider collaboration and increased citations

- maximum visibility for your research: over $100 \mathrm{M}$ website views per year

At $\mathrm{BMC}$, research is always in progress.

Learn more biomedcentral.com/submissions 